\title{
VASCULAR MALFORMATION OF CHEEK: A CASE REPORT
}

\author{
Faiz Muqtadir ${ }^{1}$, Sharanabasav Hiremath ${ }^{2}$, Surendra Agarwal ${ }^{3}$, Khalid Gufran ${ }^{4}$
}

\section{HOW TO CITE THIS ARTICLE:}

Faiz Muqtadir, Sharanabasav Hiremath, Surendra Agarwal, Khalid Gufran. "Vascular Malformation of Cheek: A Case Report". Journal of Evolution of Medical and Dental Sciences 2015; Vol. 4, Issue 15, February 19;

Page: 2617-2620, DOI: $10.14260 /$ jemds/2015/376

\begin{abstract}
Vascular lesions are among the most common congenital and neonatal abnormalities. Most of the congenital vascular malformations are often misdiagnosed and left untreated. These lesions are the result of an embryonic abnormality of the vascular system. This is a case report of 13 year male patient who came with a chief complaint of swelling on the right side of face since birth. It was diagnosed as vascular malformations of buccal mucosa of right side. It is emphasized that the management of these cases requires a multidisciplinary approach. Laser therapy, embolization followed by surgical excision is the favourable treatment modalities.
\end{abstract}

KEYWORDS: Congenital, Vascular Malformations, surgical excision.

INTRODUCTION: Vascular lesions are among the most common congenital and neonatal abnormalities. Many terms are used to refer to this lesion, notably, arteriovenous aneurysm, cavernous haemangioma, central haemangioma, pulsatile haemangioma, angioma, arteriovenous shunt, arteriovenous malformation. ${ }^{1}$ Before 1980s, vascular lesions were referred to as "haemangiomas". ${ }^{2}$ An understanding of vascular lesions has been greatly facilitated by the work of Mulliken and Glowacki. ${ }^{3}$ Thereafter the vascular lesions were subdivided into haemangiomas and vascular malformations. ${ }^{4}$ These lesions are the result of an embryologic abnormality of the vascular system. Haemangiomas are caused by a failure of differentiation in the early stages of embryogenesis. ${ }^{2}$ Usually they are extra osseous; more commonly appear in childhood and tend to regress or disappear in adolescence. They are rarely associated with fatal haemorrhages. ${ }^{5}$

Venous malformations are caused by a disturbance in the late stages of angiogenesis (Trunal stage) and result in the persistence of arteriovenous anastomosis present during embryonic life. ${ }^{3}$ they may be capillary, lymphatics, venous, arterial or mixed. They occur equally in males and females. All vascular malformations are present at birth. Although not clinically evident initially they may appear at different stages of life. The main characteristic feature of vascular malformations is that they never show signs of involution. ${ }^{6}$ Capillary, lymphatic and venous malformations are classified as "low-flow" lesions. Arterial and arteriovenous malformations are often referred as "high-flow" vascular malformations and are often the cause of massive, sometimes fatal haemorrhages. ${ }^{6}$ There are different treatment modalities, depending on the depth of the vascular malformation present, its anatomical location and extent. In general, laser treatment and or embolization favorable in most of the cases.

CASE REPORT: A 13 year male patient came with a complaint of swelling on the right side of face since birth (Figure 1). The swelling was insidious in onset and gradually progressive. The swelling was not associated with pain or fever. Extra orally, the lesion was present on right cheek region, extending from malar eminence to the upper border of mandible and from corner of mouth to the temporomandibular joint measuring around $5.5 \mathrm{~cm} \times 3.0 \mathrm{~cm}$. The overlying skin was normal. The swelling was soft on palpation (Figure 2). 


\section{CASE REPORT}

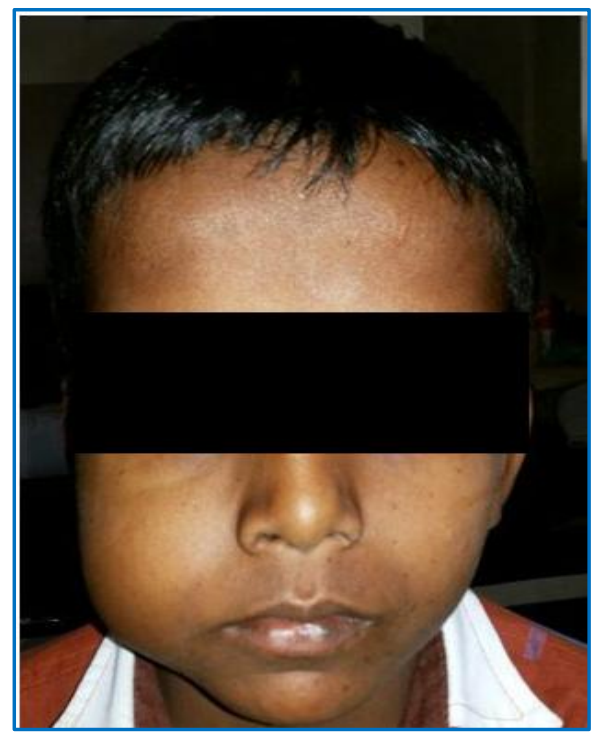

Fig. 1

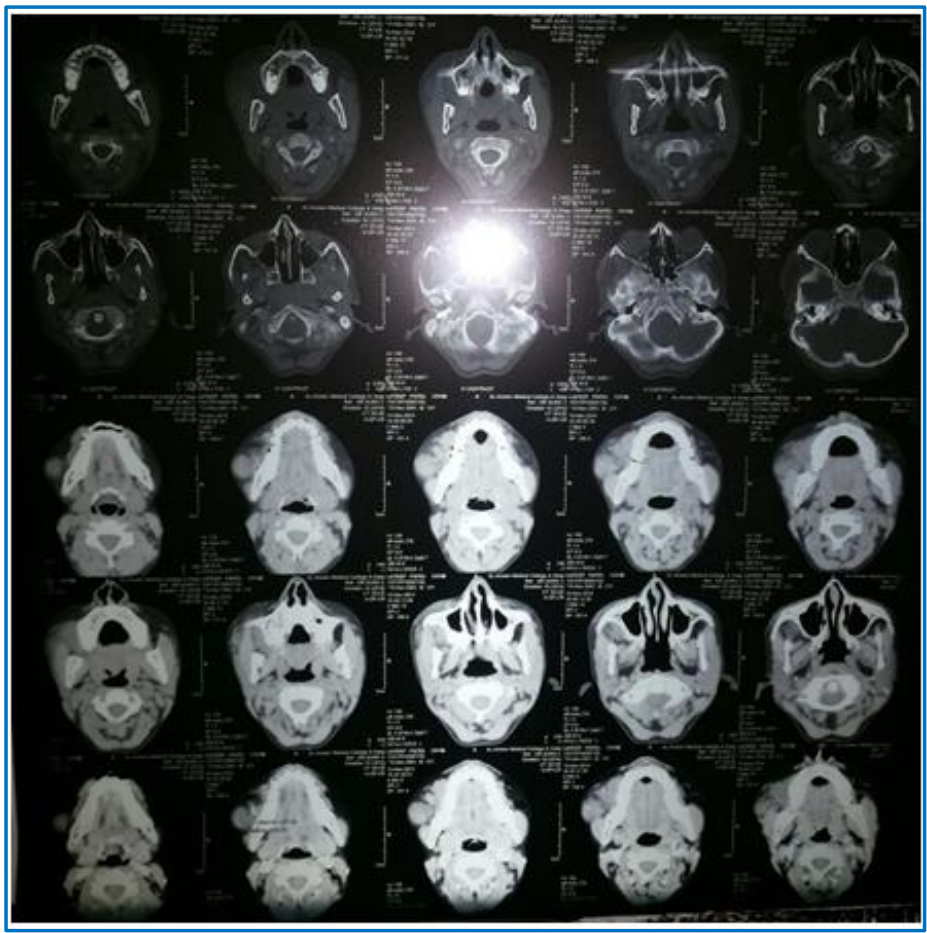

Fig. 2

Ultrasonography was suggestive of low grade vascular malformation with an ill-defined heterogenous lesion of $5.5 * 3 \mathrm{cms}$.

CT scan was suggestive of an ill-defined heterogeneous enhancing soft tissue density lesion in the deep subcutaneous plane with loss of fat planes.

The lesion was excised completely surgically with minimal blood loss. (Figure 3,4). 


\section{CASE REPORT}

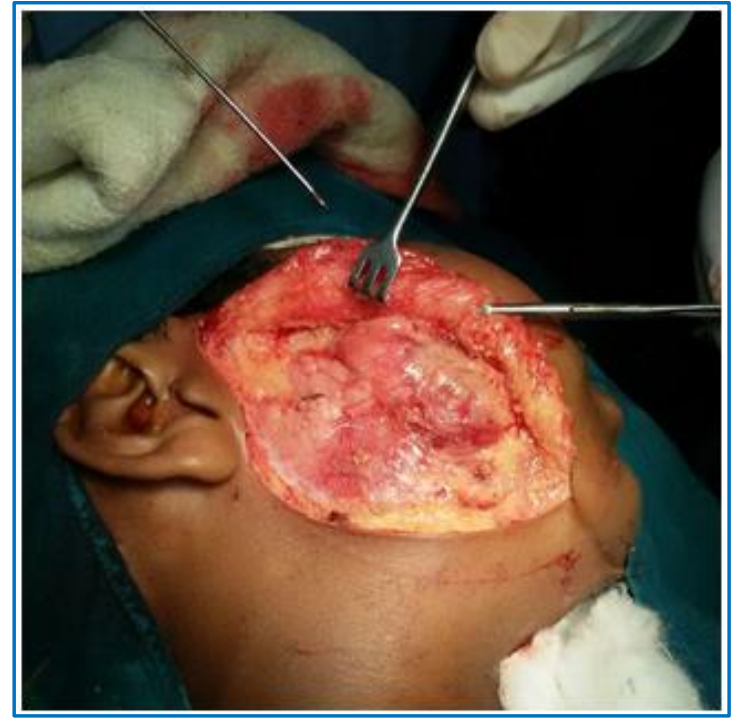

Fig. 3

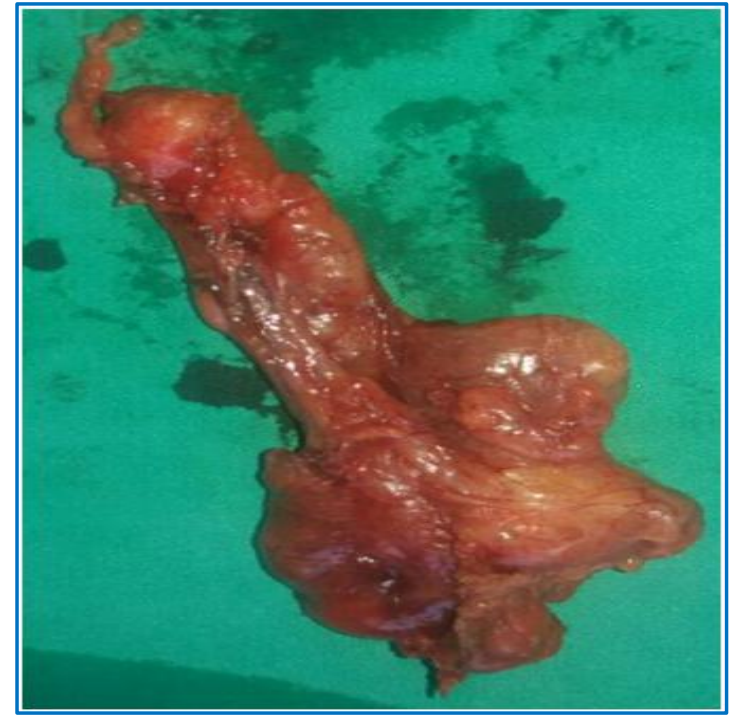

Fig. 4

There was no post-operative nerve defect or cosmetic disfigurement seen (Figure 5).

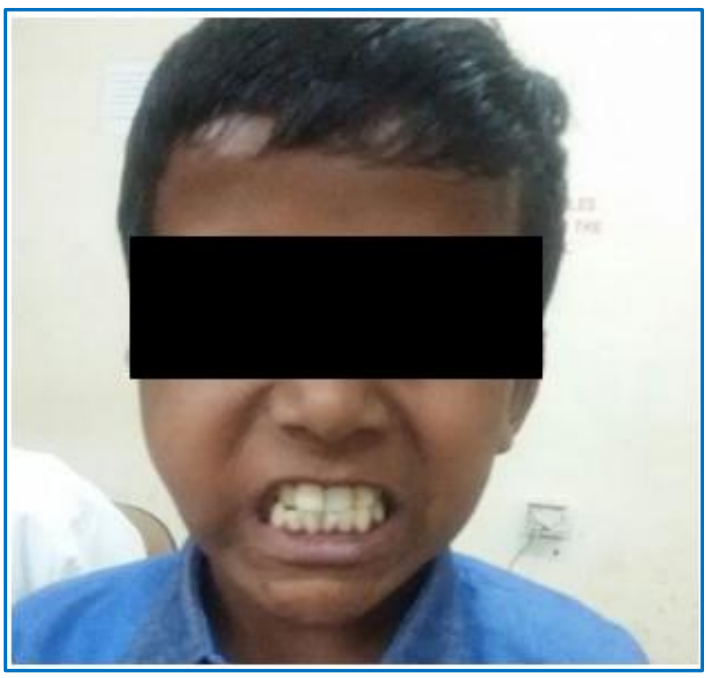

Fig. 5

DISCUSSION: There are many approaches to treat the vascular malformations. In this case the root piece of maxillary deciduous molar was extracted. Bleeding was normal and wound healing was satisfactory. Restorative treatment of rest of the carious teeth was done. The ligation of the major artery is one of the adjuvant to many approaches. But most of the authors advise strongly against it $^{2,7,8}$ because it promotes the rapid appearance of a collateral circulation since many anastomosis are there. In general, laser therapy and an embolization followed by surgical excision are the most favourable treatment modalities. Embolization consists of occluding the vessel contributing to the lesion. 
Several materials such as Polyvinyl alcohol, particles, muscle, Gelfoam, Cynoacrylate, metal coils, collagen etc have been used. ${ }^{2,9}$ Blood is redirected to the collaterals which are angiographic ally invisible due to limited perfusion, dilate as a result of the hemodynamic change and reirrigate the malformation, because of this lesion may occur.,2,9 Hence the embolization confined with surgical treatment is still the most conventional modern approach.7,9

\section{REFERENCES:}

1. Garzan MC, Enjolras O, Frieden IJ: Vascular tumors and vascular malformations: Evidence for an association. J Am Acad Dermatol 2000: 42; 275-279.

2. Kula K, Blakey G, Wright J, Terry BC: High flow vascular malformations: literature review and case report. Pediatr Dent1996: 18(94); 322-327.

3. Mutliken JB, Glowacki J: Hemangiomas and vascular malformations of infants and children: a classification based endothelial characteristics. Plast Reconst Surg 1982:69; 412- 422.

4. Glowacki J, Mulliken JB: Mast cells in hemangioma and vascular malformations. Pediatrics 1982: 70(1); 48-51.

5. Larsen PE, Peterson LJ: A systematic approach to management of high-flow vascular malformations of the mandible. J Oral Maxillofac Surg 1993: 51(1); 62-69.

6. Fishman SJ, Mulliken JB: Hemangiomas and vascular malformations of infancy and childhood. Ped Surg 1993:40; 1177-1200.

7. Mckenna SJ, Reddy SC Jr: Delayed management of mandibular vascular malformations. J Oral Maxillofac Surg: 1989: 47(5); 517-22.

8. Van Den Akker HP, Kuiperl, Peeters FL: Embolization of arteriovenous malformations of the mandible. J Oral Maxillofac Surg 1987:45(3); 255-60.

9. Anderson JH, Grisuis RJ, Mckreun TW: Arteriovenous malformation of the mandible. Oral Surg Oral Med Oral Pathol: 1981: 52(2); 118- 25.

\section{AUTHORS:}

1. Faiz Muqtadir

2. Sharanabasav Hiremath

3. Surendra Agarwal

4. Khalid Gufran

\section{PARTICULARS OF CONTRIBUTORS:}

1. Senior Resident, Department of ENT, ESIMC, Gulbarga.

2. Consultant, Department of Plastic Surgeon, Gangamai Hospital, Solapur.

3. Assistant Professor, Department of General Surgery, AMC, Bijapur.

FINANCIAL OR OTHER COMPETING INTERESTS: None
4. Lecturer, Department of Periodontics, Salman Bin Abdul Aziz University, Alkharj, KSA.

\section{NAME ADDRESS EMAIL ID OF THE CORRESPONDING AUTHOR:}

Dr. Faiz Muqtadir, H- No. 5-468/106/10, Islamabad Colony, Gulbarga.

E-mail: drfaiz.muqtadir@gmail.com

Date of Submission: 30/01/2015.

Date of Peer Review: 31/01/2015.

Date of Acceptance: 12/02/2015.

Date of Publishing: 19/02/2015. 